\title{
Erratum to: Cardioprotective and hepatoprotective effects of ellagitannins from European oak bark (Quercus petraea L.) extract in rats
}

\author{
Sunil K. Panchal $\cdot$ Lindsay Brown
}

Published online: 6 March 2012

(C) Springer-Verlag 2012

\section{Erratum to: Eur J Nutr}

DOI 10.1007/s00394-011-0277-1

In the original publication of the article, incorrect figure was placed as Fig. 5. The correct figure is reproduced below:

Fig. 5 Effects of OBE on the expression of Nrf2 and NF- $\kappa \mathrm{B}$ in the heart (a) and the liver (b). For quantitative analysis, the expression of these proteins was normalised against the expression of $\beta$-actin in the heart (c) and the liver (d). Values are mean \pm SEM, $n=3$. Means without a common letter differ, $P<0.05$. $C$ cornstarch diet-fed rats, $\mathrm{CO}$ cornstarch diet $+\mathrm{OBE}-\mathrm{fed}$ rats, $H$ high-carbohydrate, high-fat diet-fed rats, $H O$ high-carbohydrate, high-fat diet + OBE-fed rats
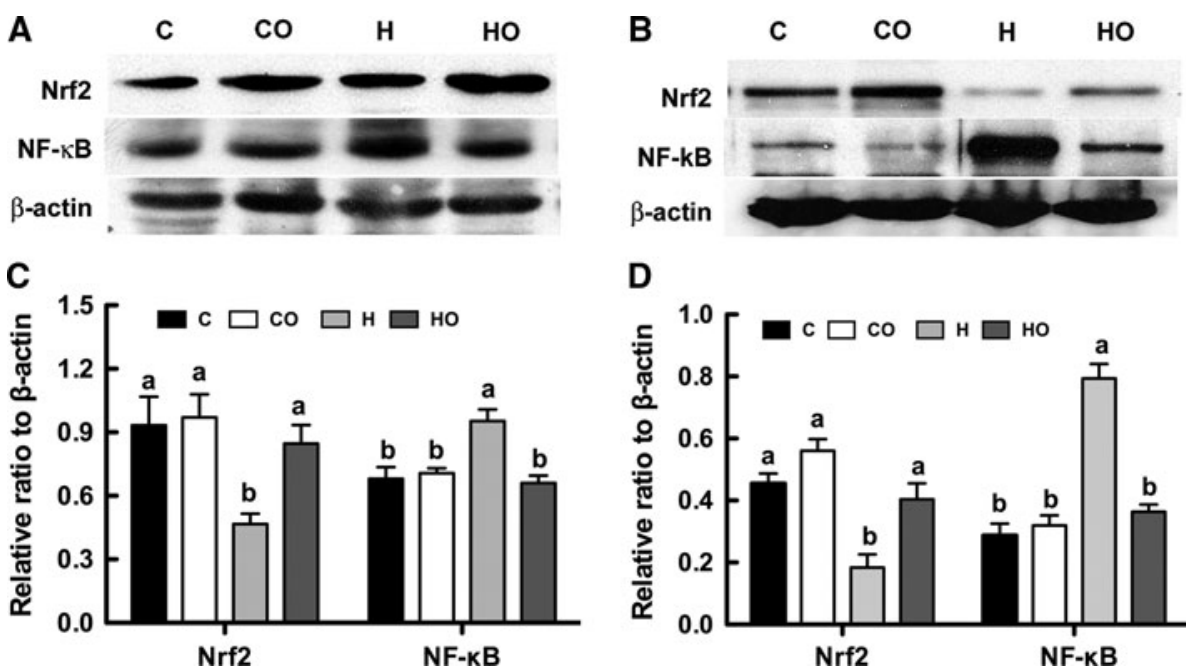

D

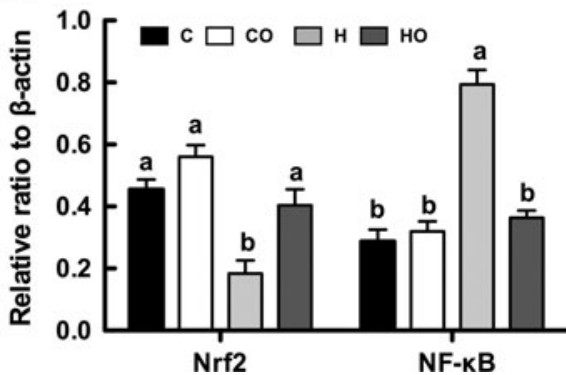

The online version of the original article can be found under doi:10.1007/s00394-011-0277-1.

S. K. Panchal · L. Brown $(\bowtie)$

Department of Biological and Physical Sciences,

University of Southern Queensland,

Toowoomba, QLD 4350, Australia

e-mail: Lindsay.Brown@usq.edu.au

S. K. Panchal · L. Brown

School of Biomedical Sciences, The University of Queensland,

Brisbane, QLD 4072, Australia 